\title{
Cervical and Lumbosacral Spinal Cord Ependymal Tumor
}

National Cancer Institute

\section{Source}

National Cancer Institute. Cervical and Lumbosacral Spinal Cord Ependymal Tumor. NCI

Thesaurus. Code C131608.

An ependymal tumor affecting the spinal cord in the cervical and lumbosacral regions. 